\title{
RICHARD AVENARIUS.
}

\author{
BY J. KODIS.
}

Chicago.

On the 18 th of last August Professor Richard Avenarius of Zurich died after a long and painful illness affecting both heart and lungs. He was still a middle-aged man, but he destroyed his health through the enormous mental effort which he made to raise modern philosophy from its present passive state to the high rank of the science of sciences, capable of directing, as of old, the thoughts and actions of humanity. In Richard Avenarius philosophy loses one of its most sincere, most devoted students, whose whole life was a sacrifice on the altar of science. For, having a high ambition, he was one of those few men who are capable of sacrificing small vanities and easy successes to a far purpose, which they do not expect to see realized during their own life. Thus he worked for the future, having for his own share nothing but disappointments and disillusions.

To read the works of Avenarius, and especially his chief book, ' Kritik der reinen Erfahrung,' is not an easy task. His terminology presents an almost insurmountable difficulty for most students of philosophy. In spite of this, Avenarius formed a school-a small one, but composed of men devoted to his ideals. He produced a complete system of philosophy, new methods of investigation of the laws of knowledge, and consequently he grouped around him a number of students, who are working in the field which he explored. The terminology that he used was partly necessary for the denomination of the new phenomena that he pointed out, but partly resulted from the extreme care which he took to prevent all possible changes as well in physiological as in psychological theories; and in consequence of this last-named peculiarity it becomes a real burden 
to read his books. This was, perhaps, the chief reason why his theory did not have at once a great success. His philosophy is not to be read, but to be studied like a treatise on mathematics or physics. But any one who undertakes this hard work will be sufficiently recompensed by the enormous wealth of ideas, new perspectives and methods, which are contained in this work.

The first philosophical paper that Avenarius published was in 1868 . It was an investigation of Spinoza's system: 'Uber die beiden ersten Phasen des Spinosischen Pantheismus.' From the time of his study of the system of this philosopher he maintained the tendency to seek for one single principle in the multiplicity of our experiences. This principle Avenarius believed was to be found in the laws of knowledge. Therefore, it was not an objective but a subjective principle on which he based his monism. Philosophy became for him a means to obtain ' a central position toward the world.' Therefore one strong and closed system of ideas, subordinate one to another, must necessarily result from this point of view.

His next paper, which was published in 1876 , ' Philosophie als Denken der Welt, gemass dem principe des kleinsten Kraftmasses,' shows three most important developments :

I. Being brought up in the psychological theories of Herbart, he endeavors to give to the facts discovered in psychical life by Herbart a biological basis. He explains the laws of assimilation of the new groups of representations by the older ones, the laws of subordination of notions one to another, etc., by the vital processes of the organism, which processes consist in the preservation, as far as possible, of the state of equilibrium, or, in other words, in the economy of the organism.

2. The general notions being formed, according to Avenarius on the same biological principle, he considers them not as entities, but rather as means directed toward the formation of our knozvledge of the world. In so far as they fulfill this purpose, they are good; when they do not serve this end, they have to be transformed to correspond to our experiences. $\mathrm{He}$ undertakes the analyses of some of the notions considered as most fundamental in modern philosophy, such for example, as 
notions of substance, matter, $\triangleleft$ Ding an sich,' etc., and finds them constructed on a false basis and rather obstructive than helpful to the development of knowledge. The notion of movement and the notion of sensation are alone sufficient to explain all phenomena. This is a kind of objective idealism, which Avenarius afterwards abandoned for realism, conserving always his critical attitude toward the general notions and trying to find the laws of the 'natural history' of their development.

3. The most important point in this paper is the subordization of psychical phenomena, as a part of life-phenomena, to general mechanical rules. Therefore it considers the biological fact of self-preservation of living organisms within certain limits as being a case of the law of stability (Beharrungsprincip). The whole psychical life is considered by Avenarius from this point of view, namely, as a function of the self-preservation of the organism, or, in case of its becoming disorganized, as the function of the self-preservation of a partial system of the organism.

'Philosophie als Denken der Welt' was announced to be the prolegomena of a larger work which followed twelve years later, in 1888 . This was the 'Kritik der reinen Erfahrung. Avenarius was impressed by the helplessness of the modern idealism, which ends with the affirmation that all we know about the world is only our sensations, $i . e$, subjective states of mind. On the other hand, he saw that in spite of those negative results of philosophical investigations the sciences increased their discoveries and human life went farther in its development, based on the belief in the reality of the objective world. Therefore he came to form the opinion that the theory of knowledge was on the wrong path, and that it was just as capable of a positive development as any other of the sciences, if only it rejected its speculative and rationalistic methods. It had only to limit itself to the facts of knowledge, to investigate them in their relations to each other, their development corresponding to the individual environment, and modifications depending upon processes of the physiological states of the organism. His critique of experience is a supreme effort to found such a science. As it is dif- 
ficult to characterize his methods in a few words, it is proper to give here, as one example, his theory of the fundamental problem of philosophy, namely, the theory of reality. In place of throwing himself immediately into a discussion as to what is reality, Avenarius seeks for other states of the human mind, having much in common with this peculiar state, which induces us to ascribe to certain phenomena the character of reality. He finds three groups of such characters, namely: the characters of existence (which includes the character of reality), the characters of security and the characters of the known (Bekanntheit). He joins them all under the common name of 'Fidencial-charactere,' which characters he considers as depending upon the exercise of the corresponding nervous processes. He explains this by the following examples:

"The exercized value 'Fatherland' is for individuals the conception of something 'existing' in the full sense of the word; and this is more exclusively the case when they spend their lives in the same place; the world at large, of which they have only 'heard' not being in this respect on the same level with their 'fatherland.' The 'fatherland' is at the same time the 'known' place of the earth on which the individual feels himself 'sure;' $i$. e., the same complex of elements are characterized by 'security' and by being 'known.' Therefore, the 'fatherland,' which is something ' known,' is in addition something 'sure' for its inhabitants, even when its situation was on the shore of the sea, like Halligen, or at the foot of an unquiet mountain, as formerly were Plurs, Goldañ, and now Elm, etc. What follows may serve as an example of the primordial unity of the three characters: "

"The 'known' path and guide, the 'known' guide-book and hotel, the ' known' newspaper and authority are also characterized as 'sure' ones. The money of the fatherland is the 'sure' money, because it is 'known,' and the longer it is 'known' the more 'sure' it is."'

Then follows an investigation of the transition of the 'Fidencial-charactere' from the positive to the negative direction, the change from 'familiarity' into 'strangeness.' Each of the

${ }^{1} \mathrm{P} .3 \mathrm{O}$ and following, Vol. Ir. 
three characters of this group can go through a line of diminishing values until it passes into a negation.

"So passes the character of 'existence' (Sein) into " appearance' (Schein), the character of 'security' into a 'lesser security,' ' the known' (Bekanntheit) into a 'lesser known'; to end in the corresponding negative characters of ' existence,' 'security' or 'the known.' On the way those characters must pass through a point of indifference."

Among the examples, given by Avenarius in such abundance as to form in reality sufficient material for a scientific induction of the laws, are the following:

"Those natures whose 'habits of life' are directed toward the continual exercise of 'realism' in the bad sense of this word, i. e., toward seeking for gain and pleasures, or in pursuing a vicious life, or in crawling and pushing (Kricher und Strebertum); such individuals give the maximum 'existential' values (maximale Existential-Werte) to the corresponding mental processes." - $(\mathrm{E}$ Werte, in the terminology of Avenarius). "If they are brought to think upon so-called 'ideal' values by their experiences, or through some communication (Mittheilung), the 'existential' difference appears proportional to the exercise. Selfforgetfulness, simple honesty, purely objective devotion, appear to them as 'less true,' ' less real,' ' more apparent,' and further are characterized as 'untrue,' ' unreal,' ' non-existent." " "So also the type of 'present,' which is the most exercised in life, possesses the strongest 'existential' characteristics; while the 'past' and the 'future' possess, in a degree corresponding to their dependence upon less exercised processes, smaller existential characteristics ; the 'present' is the ' existent,' the 'past' is the 'apparent,' which has lost its 'existence.' The 'future' will yet obtain its 'existence.' This is why the Eleatics could say of their 'being' (Sein) that it neither was nor will be, but only is, that only the unmovable and eternal being is; the 'different,' the 'becoming' (Werdende) and 'passing' is ' apparent." "

"As an especial case we obtain the expression: This color under ordinary conditions is dead-black, but on a white background it appears darker." 
It is impossible in this place to deal with the whole treatise on the characters of reality. We will add, only as an especially interesting point, that Avenarius considers the idea as possessing a character of reality which is in its modifications very near to the zero point, but on the positive side. This plain statement explains in a very simple way some of the most important philosophical misunderstandings.

The theory of knowledge given by Avenarius is, as we can easily see by the above examples, a descriptive one, but at the same time, and, perhaps even because of this fact, it is a general theory of knozledge. While formerly every theory of knowledge sought to explain how our thoughts grasp the 'existing world,' and therefore could be considered as a special theory, deriving from the individual disposition of the author, the theory of Avenarius gives a description of all those special cases of the 'explanation of the world,' and tries to induce the general laws from these facts of knowledge. The whole work is started from this point of view, that the first things given to the human mind are not abstractions, such as sensations, selfconsciousness, etc., but simply things and ideas. Therefore things and ideas should be the starting point of every philosophical investigation of the basis of our knowledge. All that we know consists only of things and ideas relating to them, and modifications of the latter more or less removed from the facts. Consequently everything in human knowledge is in some way an experience, but possessing different degrees of purity. The ideal knowledge is the pure experience which contains nothing but elements relative to the facts given by experience. Science possesses already some general notions of this purely experimental character, as, for example, the notion of energy in physics. But it is the tendency of the whole mass of human knowledge to become pure experience, in other words, to become in the highest degree adapted to the surrounding world. $\mathrm{Hu}$ manity represents, in the whole, a kind of ultra-human organism, following the same rules of self-preservation, and consequently of adaptation as any individual organism.

This last statement brings us into the very heart of the theory of Avenarius. He considers that every psychical state in living 
beings is a result of the self-preservative processes of the organism. Psychical processes accompany the physiological processes of the restoration of equilibrium in living organisms. The elementary physiological processes, consisting of a state of disturbance of the equilibrium of a partial central nervous system, and in restoration of the difference, is called by Avenarius a 'Vital-reihe,' a 'vital train.' Psychical states correlative to these physiological states are called the 'Abhängige Vitalreihe,' 'dependent vital trains.' When the equilibrium of a nervous system is disturbed it is always on account of a difference arising between the nutritive functions of the system and its work. The whole first volume of the theory of experience is devoted to a kind of general biology, describing the laws of the evolution connections, changes, etc., of such ' vital trains' in individual and social organisms. The second volume is a description of the 'dependent vital trains' as single 'psychical states,' and their especial characters, whole trains of thought, and such social products as sciences, religions, ethics, etc., being nothing else than socially developed ' dependent vital trains.' It is the first attempt in modern psychology, so far as I know, to discover the laws of the origin, development and termination of trains of thought; the theory of association explaining only (and then not entirely) the origin of thought. It is impossible to give the whole contents of the ' Kritik der reinen Erfahrung,' which furnishes indeed the outlines of a new philosophical science. The few ideas that we can speak of here can give only a very feeble impression of this, the most concise and many-sided philosophical work which has appeared since the time of the great authors of the past.

The little paper 'Weltbegriff,' which followed in I89I contains most of the things already known to students of the Critique. It is a rather popular exposition of the chief ideas of the Critique, namely, of the critical realism, which consists in the critical and conscious acceptation of the facts first given to a naive mind, namely, that the world consists of 'things' and ' ideas,' in opposition to those idealistic theories, which consider the world as ' representation' or ' will,' or 'will and representation,' etc. An especially new point in this paper is the theory 
of 'Introjection,' by which Avenarius explains the growth and formation of the theory that a fundamental difference exists between the 'inner' and 'outer' experiences. Avenarius does not find in these two kinds of experience any 'incomparability' or any 'fundamental dualism.' The idea of their essential difference has been derived, according to his opinion, from a kind of false materialism, which believed in the enclosure of the soul in the body or in a part of it, and later, in the enclosure of the faculties of the soul in the soul's substance. From this belief sprang the notion that the soul was something enclosed from the 'outer world,' into which enclosure every impression from without could come only through a putting-in, or 'introjection.' The whole modern psychology, psycho-physics and most of the philosophical theories, contain such opinions and therefore serve to strengthen the artificial wall between the 'inner' and 'outer' experiences which makes the sciences of the 'inner world' always more inaccessible to exact methods of investigation, and consequently more sterile.

Besides these chief works and a few short papers published in magazines, Avenarius was founder and editor, for 21 years, of a quarterly very well known in the philosophical world, namely, ' Vierteljahrschrift für die Wissenschaftliche Philosophie.' This magazine was founded by Avenarius and his friends, in order to develop a philosophy which would not be opposed in its chief statements to the final results of science, but would follow the same way of investigation, and conform to the growth of human experience, as the sciences have done. Among the best known authors who contributed to this journal are: Riehl, Goring, Wundt, Laass, Heinze, Windelband, Paulsen and others. 